\title{
El monopolio de la enseñanza. La cultura artesana a través de sus prácticas educativas: la enseñanza de los oficios durante la Nueva España
}

\author{
The monopoly of education. The artisan culture \\ through its educational practices: the teaching of \\ trades during New Spain
}

\section{César Gabriel Peña Ramírez*}

* Investigador independiente, Ciudad de México, México. Fue profesor de la asignatura en historia de México en el Colegio de Bachilleres en la Ciudad de México. Es licenciado en Pedagogía por la Universidad Pedagógica Nacional y maestro en ciencias con especialidad en Investigación Educativa por el Departamento de Investigaciones Educativas del CINVESTAV. Su publicación más reciente se titula "La Escuela Libre de la Razón y del Socialismo. Educación campesina bajo la bandera de la libertad" (2017) en educ@upn.mx REVISTA UNIVERSITARIA. Entre sus líneas de investigación se encuentran: Historia de la educación enfocada a los trabajadores, historia de las prácticas lectoras y escritoras de las clases subalternas, así como movimientos sociales y educación. Correo electrónico: cesarpera0508@gmail.com

(1) https://orcid.org/0000-0001-8072-3062

Historial editorial

Recibido: 24-julio-2020

Aceptado: 10-diciembre-2020

Publicado: 29-enero-2021

ISSN-e: 2594-2956 
El monopolio de la enseñanza. La cultura artesana a través de sus prácticas educativas: la enseñanza de los oficios durante la Nueva España

\section{Resumen}

El presente artículo realiza un breve acercamiento a las formas de enseñanza de los oficios artesanos en la Nueva España. Desde la historia y la antropología cultual, así como la historia social, se analizan las relaciones sociales y las prácticas educativas dentro y fuera de los talleres artesanos que contribuyeron a crear representaciones de lo que denomino el ser artesano. Se describe la estructura del taller, así como las formas de ingreso y se analizan los dos rubros más importantes que conformaron la educación artesana: la educación práctica y la educación moral. Para tales efectos, se empleó una variedad de fuentes de primer y segundo orden recuperadas del Archivo Histórico de la Ciudad de México, el Archivo Histórico de Notarías de México y la Biblioteca Nacional, Fondo Reservado. El artículo pretende desarrollar las complejas relaciones sociales $\mathrm{y}$ educativas de la cultura artesana descuidadas por la historia de la

20 educación mexicana.

Palabras Clave: Artesanos, artes y oficios, educación práctica, educación moral, gremios.
The monopoly of education. The artisan culture through its educational practices: the teaching of trades during New Spain

\section{Abstract}

This article makes a brief approach to the ways of teaching artisan trades in New Spain. Social relations and educational practices are analyzed inside and outside the artisan workshops that contributed to creating representations of what I call being an artisan from a historic, sociohistoric and cultural anthropology perspectives. The structure of the workshop, the forms of income and the two most important areas that made up artisan education (practical and moral education) are described and analyzed. For such purposes, a variety of first and second order sources recovered from the Historical Archive of Mexico City, the Historical Archive of Notaries of Mexico and the National Library Reserve Fund were used. The article aims to develop the complex social and educational relationships of artisan culture neglected by the history of Mexican education.

Keywords: Craftsmen, arts and crafts, practical education, moral education, guilds 
Le monopole de l'enseignement. La culture artisanale à travers ses pratiques éducatives: l'enseignement des métiers pendant la Nouvelle-Espagne.

\section{Résumé}

Le présent article donne un bref aperçu des formes d'enseignement des métiers de l'artisanat en Nouvelle-Espagne. Depuis l'histoire et l'anthropologie cultuelle, ainsi que l'histoire sociale, on analyse les relations sociales et les pratiques éducatives à l'intérieur et à l'extérieur des ateliers artisans qui ont contribué à créer des représentations de ce que j'appelle être artisan. Il décrit la structure de l'atelier ainsi que les formes de revenus et analyse les deux domaines les plus importants qui ont façonné l'éducation artisanale: l'éducation pratique et l'éducation morale. À cet effet, on a utilisé une variété de sources de premier et second ordre récupérées dans les Archives historiques de Mexico, les Archives historiques des notaires du Mexique et la Bibliothèque nationale, Fondo Reservado. L'article vise à développer les relations sociales et éducatives complexes de la culture artisanale négligées par l'histoire de l'éducation mexicaine.

Mots-clés: artisans, arts et métiers, éducation pratique, éducation morale, Guildes
Monopol na nauczanie. Kultura rzemieslnicza i praktyka edukacyjna: nauczanie zawodów w Nowej Hiszpanii

\section{Streszczenie}

Glownym temtem artykulu jest nauczania rzemiosła w Nowej Hiszpanii. Z punktu widzenia historii i antropologii kulturowej, a także historii społecznej, relacje społeczne i praktyki edukacyjne są analizowane wewnątrz i na zewnątrz warsztatów rzemieślniczych, które przyczyniły się do tworzenia reprezentacji tego, co nazywam rzemieślnikiem. Opisuje strukturę warsztatów, a takze dwa najważniejsze obszary, które składały się na edukację rzemieślniczą: edukację praktyczną i edukację moralną. W tym celu wykorzystano różne źródła pierwszego i drugiego rzędu odzyskane $\mathrm{z}$ Archiwum Historycznego Miasta Meksyku, Archiwum Historycznego Notariusza Miasta Meksyku i Biblioteki Narodowej. Artykuł ma na celu przedstawienie rozwoju złożonych relacji społecznych i edukacyjnych kultury rzemieślniczej, ktore zostaly zaniedbane przez historię meksykańskiej edukacji.

Slowa kluczowe: Rzemieślnicy, Sztuka i Rzemiosło, Edukacja 21 praktyczna, Edukacja moralna, Gildie 


\section{Introducción}

Cuando en el año de I769 el economista de origen irlandés Bernardo Ward dijo en su Proyecto Económico que "nada es más contrario a la industria popular que la erección de los gremios y fueros privilegiados; dividiendo en unas sociedades pequeñas al pueblo" (I769, p. I09), no solo confrontó las ideas ilustradas del nuevo régimen a las prácticas del viejo régimen, criticó el sistema gremial, su organización, su cultura, su rol político social y hasta sus sistemas de enseñanza: "En los gremios de artesanos hay poquísima enseñanza. Falta dibujo en los aprendices; escuela pública en cada oficio, y premios a los que adelanten o mejoren la profesión" (Ward, I769, p. I09).

Cinco años después, el conde de Campomanes también se refirió a la educación artesana: "Esta educación técnica y moral suele ser defectuosa y descuidada entre nuestros artesanos, persuadiéndose no pocos de que un menestral no necesita educación popular" (I774, p. 4). Ambos autores coincidían en que era necesaria una renovación de los oficios y sus sistemas de enseñanza, para que ello fuese posible, su inserción a la instrucción popular y por ende su inserción a la ciudadanía, serían de vital importancia. Según el mismo Campomanes: "Estas artes prosperan o menguan con respecto a el progreso de la instrucción nacional que las ocupa [sic] (I774, p. II).

Las críticas de los ilustrados españoles no solo estuvieron encaminadas a los privilegios de que gozaban los gremios artesanos, sino a la facultad que tenían, como tales, de establecer sus propias dinámicas y prácticas sociales, de controlar el tiempo sobre la producción, el monopolio del mercado, así como los procesos de enseñanza. Sin embargo, estas críticas tenían un trasfondo más amplio. Era la agonía de un régimen basado en la organización corporativa y cuyas prácticas no estaban acorde a los postulados de la ilustración. Mientras el sistema gremial promovía relaciones cerradas -entre agremiados- las cuales se basaban en la solidaridad cuyo fundamento fue la obra pía y en estructuras sociales bien definidas, las ideas de los ilustrados españoles intentaron 
desfragmentar estas estructuras a través de la individualización de la enseñanza, la desaparición de los gremios y la apertura del comercio con la liberalización de los oficios, objetivos que se concretarían en las Cortes de Cádiz y la posterior promulgación de la Constitución en I8I2.

La educación artesana era criticada por su pragmatismo, por su aplicación física-mecánica y poco intelectual, lo que le valió la categoría de educación práctica, pues no contaba con un sustento científico como fue el caso de la educación técnica, cuyo fundamento fue la utilización de las ciencias en el dominio de las criaturas y el uso de la "razón activa" aplicada al trabajo humano (Guerrero, I779, pp. I6-28). Sumado a ello, el monopolio de la producción, del tiempo y de la enseñanza chocó con estos postulados. Dicho "monopolio", para personajes como el propio Ward, implicó el retraso de la fábrica y la manufactura española y sus colonias. Fue pues, necesario incorporar a los vecinos de los territorios a las nuevas ciudadanías, y para eso la educación debía ser una herramienta de civilización y progreso. Para el jurista Gaspar Melchor de Jovellanos, la educación debía ser palpable, observable. Decía: "Entre todas las criaturas solo el hombre es educable, porque él solo es instruible" finalizaba asegurando que "educarle no es otra cosa que ilustrar su razón con los conocimientos que pueden perfeccionar su ser. Por eso decía el gran canciller de Verulamio, que el hombre vale lo que sabe" (Jovellanos, I865, p. 64).

La realidad es que la educación artesana proveía de una cultura ligada al trabajo y la vida cotidiana. Para muchos gremios, el taller artesano, también conocido como obrador, no solo fue un espacio dedicado al trabajo, por el contrario, fue también un espacio pedagógico y de socialización que generaron una serie de representaciones sobre qué era el ser artesano. El espacio, la materialidad, los roles y las estructuras sociales, los barrios, los lenguajes y las ordenanzas influyeron en las formas de concebir el mundo y generar una cultura, a esto Sewell (I992) lo denomina ethos artesano. Los elementos anteriormente descritos se conjugaron con la educación, la cual tenía un peso fundamental sobre el desarrollo de este ser artesano. Por ende, la crítica de los ilustrados españoles a 
los sistemas gremiales -y con ello a sus métodos de enseñanza- tuvo implicaciones más complejas que solo la actualización de los oficios, fue el confrontamiento de dos visiones en torno a la educación, la cultura y el mundo. Fue una disputa sobre quién, qué o quiénes podían y debían tener el control de la educación.

El objetivo de este artículo es describir y analizar los sistemas de enseñanza artesanos los cuales estuvieron basados en una serie de relaciones complejas que implicaron el trabajo y la vida cotidiana. Por un lado, el trabajo generó una cultura y la cultura una visión del mundo. Campomanes describió esta educación en dos sentidos: la técnica (práctica) y la moral. La primera estuvo relacionada a la enseñanza de los oficios, mientras que la segunda se encargó de enseñar a los artesanos prácticas como la solidaridad, el honor, la cristiandad y los "buenos hábitos". Si bien, el tema de la educación artesana ha sido tratado por la historiografía mexicana, son escasos los trabajos que se adentran en la educación como formadora de representaciones, de cultura y de simbolismos.

\section{La conformación del taller}

El taller, a diferencia de otros sistemas laborales, fue un sistema en el que se conjugaron relaciones de producción y familiares. Esto es, en la elaboración de productos participaron mujeres y varones por igual; sin embargo, y por lo general, las ordenanzas establecieron una estructura tripartita (Barrio, I92I) la cual estaba conformada por:

I. El maestro artesano como cabeza del taller. Generalmente era dueño del taller y quien dirigía la enseñanza del oficio.

2. El oficial, quien también podía ser conocido como mancebo, compañero o laborante. Era la mano derecha del maestro, pero su posición dentro del taller fue de más relevancia, pues comúnmente era quien sostenía económicamente el trabajo. En ocasiones, cuando el maestro se ausentaba, el oficial tomaba la batuta como enseñante del oficio.

3. Finalmente, el aprendiz. Los aprendices podían ser niños, jóvenes o adultos. Los primeros dos debían estar acompañados de sus padres 
o tutores, quienes acordaban previamente la inserción de los jóvenes al taller, mientras que los adultos se acercaban a los maestros de manera voluntaria pactando la enseñanza (Somohano, 200I; Carrera 1954).

Para acceder a la maestranza, el artesano no solo debía atravesar por un difícil proceso de educación que implicaba el aprendizaje del oficio, el cual duraba años, sino por una serie de examinaciones económicas, morales y prácticas que corroboraran su posición como aspirante a maestro. El historiador mexicano Manuel Carrera Stampa relata que el artesano debía "no ser aspirante al camorreo, no juntarse con gente de baja estofa, ser de genio apacible y sosegado, temeroso de Dios y de conocida calidad, procederes y costumbres" (1954, p. 5I). Contadas ordenanzas gremiales establecieron que algunas castas (indígenas, mestizos o negros) no podían acceder a la maestranza, aunque ello no implicó que pudiesen aprender y ejercer el oficio.

Algunos otros requisitos para acceder al examen de maestro fueron: ser varón, tener una edad en la que fuera legalmente responsable (Castro, 1986) y, en casos como el gremio de escribanos, el cual trabajaba para el cabildo de la Ciudad de México, debía demostrar "su limpieza de sangre, costumbres cristianas y buena crianza familiar [sin] que en eso se dispense en un ápice, pues tales cualidades estimulan a las buenas operaciones" (AHCM, s/f, Copia que informa). Otros gremios como los plateros y joyeros también establecieron la pureza de sangre como condición para acceder al título.

Si el aspirante cumplía con estas condiciones y presentaba un buen examen acreditándolo (AHCM, I752) obtenía su acta de examinación que lo obligaba a aperturar un taller público y enseñar los secretos del oficio (AHCM, I770). 


\section{Ingreso al oficio}

El aprendiz, como su nombre lo dice, era quien se encontraba en el escalón más bajo en la estructura del taller y quien iniciaba el largo proceso en la formación del artesano. Una vez decidido el oficio, los padres o tutores se acercaban al maestro artesano manifestando su idea de ingresar al joven. Aunque a lo largo de la Colonia las corporaciones gremiales estuvieron conformadas en su mayoría por criollos y peninsulares, se sabe que existieron trabajadores de otras castas y que incluso accedieron al título de maestro (AHCM, I752). En muchas ocasiones, la finalidad de entregar a un joven al maestro y que aprendiera un oficio se relacionaba con la búsqueda de la independencia económica.

Antes de ser aceptado de manera definitiva, el aprendiz debía atravesar por una serie de examinaciones realizadas por el maestro. La examinación podía tener una duración de un mes en donde el maestro valoraba las destrezas del joven. Si el maestro decidía aceptar al joven aprendiz como su alumno se celebraba un contrato o "pacto" entre los padres y el maestro o bien entre el maestro y el aprendiz. El contrato se hacía ante notario (escribano) y se establecía el periodo de aprendizaje y los compromisos que adquiría cada uno.

Lourdes Somohano (200I), en su estudio sobre los aprendices de obradores queretanos, realizó un análisis de las variables "edad" y "periodo de años establecidos en los contratos", mostrando que, mientras más joven era el aprendiz, mayor era el número de años que se establecían para el aprendizaje. Por el contrario, a mayor edad, menor era el periodo. Si el aprendiz ingresaba a los 9 o Io años de edad, el periodo de aprendizaje era de cuatro años. Si lo hacía entre los II y los 24 años de edad el promedio era de tres años, y de 25 en adelante se establecían como mínimo dos años de aprendizaje. Por lo que se puede inferir que, por una parte, el estatus de "aprendiz" se refería más bien a la edad que al cúmulo de conocimientos adquiridos; por la otra, que el aprendizaje implicaba una relación de tutoría o guía por parte del maestro en la formación de los jóvenes. 
Algunas ordenanzas halladas en el Archivo Histórico de la Ciudad de México permiten observar que el periodo mínimo como aprendiz era de dos años. Además de prohibir la contratación de aprendices por parte de oficiales, debido a las deficiencias en los trabajos, las ordenanzas establecen que el tiempo de aprendizaje no podía ser breve. Debía haber un "maestro para poderlo usar porque de tomarlos por poco tiempo y por dádivas que les dan, por ello quedan los tales Aprendices sin saber el dicho oficio, y las obras que hacen son malhechas y cuando han de saber y aprender el dicho oficio, puesto que han cumplido el tiempo, se van y quedan remendones [sic]", por ello se establecía que el aprendizaje durara "a lo menos que sea el tiempo por dos años" (AHCM, s/f, Ordenanza que informa; AHCM, I753). De no cumplir con la ordenanza las amonestaciones iban desde una llamada de atención hasta una multa económica que podía variar según el gremio (Barrio, I92I).

Respecto a las obligaciones y deberes, el aprendiz se comprometía a: I) prestar el servicio en persona; 2) guardar fidelidad a su oficio y al gremio, es decir, no incurrir en deslealtades tales como divulgar secretos profesionales; 3) prestar auxilio en el momento en que peligrara el maestro, sus intereses o los del gremio; 4) cuidar las herramientas y utensilios de trabajo; 5) ser una persona de buenas costumbres; 6) obedecer, servir y respetar al maestro; 7) guarecer la vida privada del maestro y 8) poner empeño, cuidado e intensidad a su aprendizaje. (AHNM I793; AHNM, I79I; Carrera, 1954). Otros compromisos que no se explicitaban en los contratos fueron: la realización del aseo y los mandados tanto del taller como de la casa del maestro. Por momentos, estas tareas generaron tensiones entre maestros y aprendices, pues estos últimos consideraron como abusivas este tipo de prácticas (Carrera, I954).

Por su cuenta, las obligaciones del maestro eran, además de enseñar el oficio: alojar al aprendiz en su casa, brindarle vestimenta y un sueldo. Por lo general, aprendices y oficiales dormían en el taller conviviendo las 24 horas del día. La vestimenta constaba de un paño al inicio y a mitad del periodo de aprendizaje y cuyo único propósito solo era el de cubrir su desnudez. Si las condiciones económicas del 
maestro lo permitían, al final del aprendizaje se le obsequiaba ropa digna de su oficio. En cuanto al sueldo, este se materializaba en alimento y en casos de enfermedad, en medicamento. Solo cuando la enfermedad se extendía más allá de los quince días, los gastos médicos corrían por parte de los padres o tutores (AHNM, I786).

Finalmente, el maestro se comprometía a ser una figura virtuosa y moral al que se "encomendaba el cuidado de la buena conducta y costumbres de sus discípulos así como la dedicación al oficio aprendido" (Pérez, I996, p. 60). Para Felipe Castro, este contrato representó "una forma de cesión de la patria potestad. El joven no podía abandonar a su maestro y a él lo entregaban cuando era sorprendido ebrio o alborotado por las calles" (I986, p. 74).

\section{El ser artesano}

Pierrotti (2015) y Carrera Stampa (1954) coinciden en la similitud que tenía el obrador con una escuela de artes y oficios; sin embargo, las relaciones que se establecieron dentro del primero fueron más complejas aún. Los talleres se convirtieron en espacios epistemológicos, pedagógicos, de sociabilidad y de producción. Si bien coincido con Carrera (1954) en que uno de los fines últimos de esta educación era la adquisición del título de maestro, la enseñanza y el aprendizaje del oficio constituyeron más que eso, permitieron la formación de representaciones sobre el ser artesano y su rol político, económico y social. El Diccionario de Autoridades de la Real Academia (Real Academia Española, I726) define al artesano como: "Oficial mecánico, que gana de comer con el trabajo de sus manos: y con especialidad se entiende del que tiene tienda pública”. Por otro lado,

28 algunos ilustrados españoles, como Ramón Miguel Palacio, consideraban que "estos cuerpos combinados [se refiere a los gremios] emprenden abastos, y rápidas expediciones; promueven fábricas, costean máquinas, y dan un gran impulso a la industria de economía, y al comercio activo [sic]" (p. 49), lo que demuestra la complejidad de la formación artesanal. 
La antropóloga cultural Jean Lave (200I) plantea que las relaciones existentes dentro de los talleres constituyen un "aprendizaje situado", es decir, generan un tipo de conocimiento que es contextualizado (social e históricamente) que, pese a ser cotidiano no es prosaico, que se construye socialmente por medio de "aparatos culturales" y que tiene implicaciones en la construcción de la identidad. Por ello, durante el periodo de formación de los aprendices, estos no solo desarrollaban habilidades técnicas que les servían como sello de su arte, sino que las relaciones dentro de los talleres y la relevancia del oficio eran constitutivas de su personalidad, con un fuerte arraigo a su labor y con un sentido de pertenencia propio de cada oficio. El historiador Robert Darnton lo ilustra con su descripción sobre el detallado trabajo de los tipógrafos franceses:

En el siglo XVIII [los libros] se hacían a mano. Cada hoja de papel se producía individualmente por medio de un procedimiento complicado y cada hoja era diferente de las otras del mismo volumen. Cada letra, palabra y línea se componían de acuerdo con un arte que le daba la oportunidad al artesano de expresar su individualidad. Los mismos libros eran individuos, cada ejemplar poseía su carácter propio (2018, p. 254).

Se pueden identificar dos rasgos interesantes en la formación de la identidad artesana: la primera es fuera del taller y la segunda dentro. Los rasgos identificados me permiten sugerir que además de aprender el oficio, se constituían representaciones sobre las formas del ser artesano y sus visiones del mundo.

Fuera de los talleres, tenían una relevancia significativa las festividades realizadas a los santos patronos de las diversas corporaciones. Cada gremio tenía su propia cofradía y, por ende, cada gremio contaba con su santo o santos patronos. A su vez, "algunas cofradías o hermandades poseían capilla propia o el patronato de un altar en alguna iglesia parroquial, en un convento, monasterio $u$ hospital" (Carrera, I954, p. 9I). Las ordenanzas establecían que los artesanos debían cooperar económicamente con los gastos para las festividades de los santos. La cooperación variaba según el tipo de 
gremio. Además, parte de los requisitos para la examinación era el pago para las festividades santas (AHCM, I770; Barrio, I92I).

Era obligatoria la asistencia a las festividades, "se oía misa de réquiem con toda solemnidad, comunión general y sermón, en el que se exaltaba la vida del Santo Patrón como modelo de virtud para todos los cofrades". Posteriormente "todos los agremiados tenían la obligación de asistir a las procesiones acompañando las imágenes de los santos titulares" (Carrera, I954, p. 94). Como señala Torres (2012), las festividades coadyuvaron en la cohesión de estos grupos, ya que la asistencia a las festividades, a los sepelios o a las procesiones generaron un sentido de pertenencia a dichas corporaciones, sumado a ello, la base de la solidaridad fundada en la obra pía generó un sentimiento de fraternidad ante la enfermedad, la pobreza y la muerte.

Fuera de las festividades, en la vida cotidiana, los barrios y las calles también cumplieron un papel importante en la conformación de la identidad: "Por la mañana se abrían las puertas de tiendas y talleres y muchos artesanos sacaban a la calle sus instrumentos de labor" (Gonzalbo, 20I2, p. I06). Por lo que era común encontrar a maestros, oficiales y aprendices en el vaivén de la labor. Esta rutina de trabajo callejero "era tan reconocida que ya algunas calles se nombraban por el artesano que se establecía a la intemperie: durante años, a lo largo del siglo XVIII, se conoció la esquina 'del banco del herrador"' (Gonzalbo, 20I2, p. I06). La famosa calle de Madero en el Centro Histórico de la Ciudad de México tuvo anteriormente el nombre de Plateros, debido a que muchos talleres artesanos dedicados a la platería se encontraron establecidos en aquel lugar. Actualmente es posible observar diversa variedad de tiendas de joyería en aquella calle, lo que supone la pervivencia de la cultura artesana.

En menor medida, pero no por ello poco significativa, la indumentaria también jugó un papel importante en la identificación como artesano. La vestimenta permitía diferenciar a los trabajadores de la población marginal, pues era "común ver a los individuos pertenecientes a las clases trabajadoras exhibiéndose por todos los 
lugares de la ciudad con ropa sucia, en malas condiciones o semi desnudos al lado de la población indigente o marginal, debido muchas veces al trabajo mal remunerado o a la falta de ésta" (Mota, 2004, p. 128).

No muchos artesanos contaron con ropa que los identificara como tales, como ya se mencionó, los maestros generalmente entregaban un paño que cubría los cuerpos de sus aprendices y solo en contadas ocasiones recibieron vestimenta digna que los diferenciara de otros grupos. Pese a estas circunstancias, muchos artesanos lograron distinguirse por la suciedad de sus ropas y de sus cuerpos, características que los hacían inconfundibles (Mota, 2004). Por lo que la ropa, más que ser característica del artesanado, fue un medio por el que la suciedad los distinguió como trabajadores.

\section{Educación práctica}

Dentro del taller, y donde se llevaba a cabo el proceso de enseñanza de los oficios, la rutina era la que constituía el sistema de aprendizaje. El espacio físico, el tiempo y las relaciones sociales fungieron como "aparatos culturales". Pese a las críticas que recibieron las corporaciones durante el siglo XVIII, esta educación no fue improvisada, por el contrario, la información que proporcionan las fuentes indica una serie de "procesos bien definidos" (Pierrotti, 20I5, p. II6). Una constante crítica realizada por los ilustrados españoles fue la poca perfección de los oficios, debido a la carencia de herramienta y la deficiente idea de innovar tanto en sus procesos de producción, como con la entrada de nueva herramienta que les permitiera acelerar el trabajo y mejorar sus productos: "Regla general: así la forma como el número de los utensilios de un taller manifiestan infaliblemente el estado de las artes al hombre que observa: este estado indica el bien, o malestar del artesano. Entre mendigos hay poca perfección que exigir; si se trabaja con tosquedad un armario, con la misma se labra una cerraja [sic]" (Palacio, I778, p. 45). 
Si bien la resistencia de los artesanos a la innovación y a los cambios se mantuvo por largo tiempo, Lave (1993) plantea que, pese a que este tipo de educación suele ser generacional, es decir que se transmite de una generación adulta a una joven, no es posible descartar las habilidades de los jóvenes aprendices, quienes contaban también con una serie de conocimientos previos. Esto permitió que a pesar de lo rutinario del aprendizaje: I) se dieran procesos de innovación y cambio en la elaboración de productos y 2) no se afectara la individualización artesana, en otras palabras, el artesano se sentía parte de una comunidad, pero ello no le valió olvidar quién era como individuo y cuál era su papel dentro de la comunidad a la que pertenecía (Lave, 1993).

Un tema relevante dentro del taller fue el tiempo. Los artesanos no solo tenían el monopolio de los mercados y de la educación que impartían a sus agremiados, sino también la capacidad de controlar los procesos de producción a través del tiempo (tema que también fue cuestionado desde planteamientos económicos liberales en el siglo XVIII y XIX).

Para los artesanos, el tiempo era relativo respecto a sus obras, es decir, no había un establecimiento de carga horaria. El trabajo se llevaba a cabo según el trato que se establecía con el cliente o los trabajos pendientes que había dentro del taller, circunstancia que cambió con el establecimiento de las fábricas. Rudolf Rocker, anarquista alemán, relataba sobre su experiencia laboral como artesano: "El trabajo no era tan cansador como en el barco, pero no existía una determinada jornada. Trabajábamos, doce, trece y hasta catorce horas por día. Hasta el domingo se trabajaba por la mañana, de modo que me quedaban muy pocas horas para ir por la tarde a la ciudad y ver a mis parientes" (1967, pp. 2I4-2I5).

Según el historiador inglés Edward Thompson, en el sistema artesanal el tiempo se convertía en una propiedad (posesión), pues se controlaban los tiempos de producción, mientras que en el sistema capitalista "el patrón debe utilizar el tiempo de su mano de obra y ver que no se malgaste: no es el quehacer el que domina sino el valor del 
tiempo al ser reducido a dinero. El tiempo se convierte en moneda: no pasa sino que se gasta" (I984, p. 247). Gracias a este control del tiempo, el maestro podía llevar a cabo una constante vigilancia y guía sobre los aprendices y los oficiales, lo que le permitía orientar de mejor forma las actividades y fortalecer los problemas que podían encontrarse en el camino (Lave, 1993). Cabe mencionar que, en algunas ocasiones, la enseñanza quedaba a cargo de los oficiales o de otros aprendices con más tiempo dentro del obrador. Ello podía dificultar el aprendizaje, pues por momentos, oficiales y aprendices con más tiempo veían en los nuevos integrantes no sólo una competencia dentro del taller, sino una amenaza a futuro debido a que las ordenanzas limitaban el acceso a la maestranza, regulando los oficios y evitando la excesiva competencia entre agremiados.

Finalmente, el aprendizaje del oficio logró estimular el desarrollo de habilidades de lectura, escritura y el uso de las matemáticas aplicadas. Estas habilidades se debían sobre todo a la disposición y autodidactismo que muchos aprendices desarrollaron durante su estancia en los talleres, reflejando que la enseñanza de los oficios tenía múltiples beneficios, los cuales se concentraron en el ámbito laboral y que también repercutieron en su formación personal, aprehendiendo signos culturales que desarrollaron el ser artesano.

\section{Educación moral}

La enseñanza de la moral fue muy importante en la educación de los artesanos, sobre todo en su práctica cotidiana, ayudando a complementar el aprendizaje práctico. La moralidad era una práctica transmitida de generación en generación y que correspondió más a las "sociedades tradicionales", las cuales tenían como objetivo desarrollar creencias, valores y modales (Lave, I993). En los contratos, el maestro no solo se comprometía a enseñar el oficio, sino que también "se compromete el contratante a educarlo 'civil y cristianamente y castigándole sus defectos con moderación”" (Somohano, 200I, p. 50). El compromiso que adquiría el maestro le convertía en un paterfamilia, pues no solo guiaba al aprendiz por la 
educación práctica, sino que también le educaba "moral y espiritualmente", con base en las prácticas religiosas influenciadas por las cofradías eclesiásticas. Para Sewell "las relaciones de producción en los oficios artesanales eran sociales, no solo en lo institucional, sino también en lo moral. Las corporaciones, además de ser unidades de regulación y disciplina, también eran unidades de profunda solidaridad" entre las que existía una "comunidad moral": "Pero la comunidad moral del oficio se manifestaba sobre todo en la vida religiosa de la corporación” (Sewell, citado en Pérez, I996, p. 66).

La comunidad moral tenía su fundamento en la llamada obra pía (ejercicio de caridad) la cual fue transformándose en relaciones de solidaridad entre agremiados, siendo identificada por el geógrafo ruso Piotr Kropotkin como redes de "apoyo mutuo". Es necesario aclarar que estas relaciones no siempre fueron pacíficas o tersas, pues tanto fuentes primarias como secundarias ilustran los diversos conflictos que existieron dentro y fuera de los talleres e incluso entre distintos gremios. A pesar de las diferencias, en momentos de infortunio los artesanos demostraron su unión, y cuyas prácticas pueden observarse de mejor manera en documentos del siglo XIX.

No han podido hallarse fuentes anteriores al siglo XIX que ilustren las relaciones de solidaridad artesana; sin embargo, me propongo ejemplificar estas prácticas a través de documentos consultados en el Archivo Histórico de la Ciudad de México, fondo Ayuntamiento, sección Vagos, de manera particular en expedientes que corresponden al llamado Tribunal de Vagos, creado en el año de i828 (AHCM, I828). Aquí es posible observar de viva voz las prácticas relacionadas con la solidaridad y las redes de apoyo mutuo.

34 La liberalización de la producción, la apertura de los talleres y la abolición de los exámenes gremiales, para fomentar el desarrollo de los oficios a partir de las Constitución de Cádiz, trajo consigo una serie de consecuencias graves para los artesanos del México independiente: falta de empleo, vagancia e incremento de los vicios, fueron algunos signos por los que atravesaba este sector de la población. En el año de I828 se creó el Tribunal de Vagos, cuya 
finalidad fue corregir los "malos comportamientos" de los ciudadanos. Sin embargo, estas fuentes son de relativa importancia, pues nos permiten observar las diversas relaciones y prácticas cotidianas que se establecieron entre artesanos de diversos talleres y gremios. Entre los ejemplos que pueden encontrarse en los volúmenes que integran el Tribunal de Vagos de la Ciudad de México, existen documentos que refieren la detención de Juan Guerrero y de Pedro Salinas, el primero impresor de veintiún años de edad, el segundo carpintero sin especificar su edad. Juan Guerrero se encontraba paseando "casualmente en la calle de Tiburcio en compañía de otros hombres" cuando se encontró una "Bayoneta". Intentando buscar a su dueño fue detenido junto a Pedro Salinas, a quien preguntaba si el cuchillo le pertenecía. Salinas declaró no conocer a Guerrero y afirmó que, por el hecho de estar en compañía de otros sujetos a altas horas de la noche, a Guerrero se le debía considerar un "vago", añadiendo: "por lo que es digno que se le aplique el castigo que la ley demarca a esta clase de delincuentes" (AHCM, I829, exp. 15).

En este ejemplo es posible encontrar diferentes discursos. Por un lado, Pedro Salinas consideraba vago a Guerrero por el hecho de estar caminando a altas horas de la noche en compañía de otras personas, quienes eran artesanos del mismo oficio, pero no queda claro si del mismo taller. Mientras que Salinas, saliendo de su trabajo y sin conocerle, no debía ser castigado pues era "hombre trabajador y de bien". En ambos casos se expresó la solidaridad por parte de los artesanos de cada oficio, al enviar misivas en las que certificaban conocer a los inculpados. Una de ellas, en apoyo a Salinas, decía:

Por este digo y respondo por Pedro Salinas que cuando trabajó conmigo nunca dio nota de su obrandía si bien en los días que estuvo conmigo trabajando en mi taller de Carpintería. Y para que coste lo firmo en el día 2 de Julio de I829. José Robles [sic] (AHCM, I829, exp. I5).

En otra carta, un oficial llamado Manuel Oliva aseguraba que Salinas era un "hombre de Bien", además de "estar casado con Carmen 
Arriaga" y "dedicarse al sostenimiento de su esposa". Por otra parte, en apoyo a Juan Guerrero, Antonio Alcalde, otro maestro, escribió:

Certifico que el ciudadano Juan Guerrero es hombre de bien, de oficio impresor en el ramo de composición y ha trabajado en la oficina del ciudadano Martín Rivera y obra; y aun lo he solicitado para que venga á trabajar á esta oficina que lo es la de la testamentaría de Ontiveros por ser joven muy apto para el arte (AHCM, I829, exp. 15).

Salinas fue declarado inocente mientras que Juan Guerrero fue culpado del delito de vagancia. Días después una extensa carta de Miguel Floripey [sic], maestro artesano con quien colaboraba Guerrero, apeló a su inocencia, pues "primeramente debemos llamar vago y mal entretenido, todo aquel hombre vicioso que subsiste de la rapiña y no posea ningún arte; mi ahijado en este caso no merece titulársele tal vago cuando se ejercita en la Imprenta y subsiste de ella”. Las fuentes no indican cuál fue el destino de Guerrero.

Esta última carta permite observar las prácticas de solidaridad y así mismo las representaciones que este grupo tenía de sí mismo y de otros trabajadores como ellos. En primera, la denominación "ahijado" refuerza el sentido de paternalismo con que se ha caracterizado a los maestros. En segunda, la percepción que entre artesanos se tenían al trabajar y formar parte del oficio, considerando como injusto el trato y el concepto que se tenía de ellos.

Independientemente de cual haya sido el desenlace de ese caso, se sabe que, en muchas ocasiones, cuando los artesanos eran liberados, ya fuesen oficiales o aprendices, las autoridades encomendaban la enseñanza del oficio, así como el cuidado de su conducta al maestro 36 del taller, reforzando la obligación de este a ser un ejemplo por medio de la firma de una carta compromiso (Pérez, 1993). 


\section{Conclusiones}

La historiografía mexicana ha hecho énfasis en el vínculo que se estableció entre la enseñanza de los oficios en los talleres artesanos y las escuelas de artes y oficios posteriores a la Independencia. Los relativamente pocos estudios dedicados a la enseñanza dentro de los obradores también han tenido su foco en la estructura del taller y en las relaciones sociales de una manera superficial. Todo esto se debe a la poca documentación a la que se puede acceder, ya que escasos artesanos elaboraron textos que nos permitan tener un acercamiento más profundo a sus relaciones cotidianas. Sin embargo, el análisis profundo de estas fuentes, la comparación y paralelismo entre gremios europeos y americanos, el análisis de las ordenanzas y mayor aún, las formas de enseñanza del oficio que perviven en nuestros días, nos permiten tener aproximaciones cada vez más certeras sobre los métodos de enseñanza $y$, sobre todo, de las prácticas que comprendían el ser artesano.

A lo largo del artículo se ha develado que las relaciones educativas y sociales al ingreso en el taller, fueron más complejas. Quien ingresaba a un taller artesano lo hacía no solo como trabajador, por el contrario, la relación trabajo-vida cotidiana estableció una serie de redes sociales, que si bien eran limitadas, pues se mantuvieron dentro del gremio, se basaron en lo que Kropotkin (1989) denomina "apoyo mutuo". La solidaridad fue fundamental para mantener viva su cultura y sobre todo las formas organizativas que pervivieron o que influyeron en organizaciones como las sociedades de socorros mutuos, durante la segunda mitad del siglo XIX. Este asociacionismo estuvo acompañado por una serie de prácticas que constituyeron y reforzaron la identidad artesana. Las festividades, la ropa, los barrios, los gremios, las ordenanzas, la vida diaria y la educación fueron prácticas que generaron representaciones sobre el ser artesano.

La educación jugó un papel importante en la conformación de la identidad. A través de las fuentes se pudieron identificar dos grandes esferas que constituían la educación artesana: la primera fue la enseñanza práctica o del oficio, la cual no estuvo signada solamente 
al uso de la herramienta y la creación de artículos para su uso o consumo cotidiano, sino que representó una serie de signos y significaciones culturales que identificaron al artesano como tal. Los aprendices y oficiales convivieron juntos por años, aprendían los secretos del oficio, compartían al maestro, usaban el mismo lenguaje y tenían sus diferencias. Ello contribuyó a generar relaciones fuertes, pero no por ello estables. Sería ingenuo pensar que las relaciones establecidas en los talleres siempre fueron las mejores. La competencia entre artesanos también se convirtió en una constante batalla por acceder a la maestranza, ya que las ordenanzas establecieron una regulación sobre la cantidad de artesanos que podían ascender a tal título y cuya finalidad fue evitar la competencia desleal entre agremiados. Estas constantes fricciones y tensiones entre artesanos de un mismo oficio obligaron, sobre todo a los oficiales, a recurrir a prácticas "desleales" como aperturar talleres clandestinos, sin haber presentado examen de maestranza y sin permiso de los gremios.

La segunda esfera fue la educación moral. Esta educación podría verse como un círculo, ya que el artesano que lograba llegar a la maestranza debía cumplir con una serie de requisitos que lo obligaban a ser un hombre virtuoso. La base fundamental de este virtuosismo fue la moral cristiana. Como un padre de familia, el maestro debía transmitir estas virtudes a través de las prácticas cotidianas. A su vez, los aprendices que se convertían en oficiales y posteriormente en maestros, debían enseñar o transmitir los conocimientos prácticos y morales a las siguientes generaciones, lo que permitió el sostenimiento de este grupo por varias décadas, una vez abolidos los gremios en el siglo XIX.

Como sucedió con la enseñanza práctica, la enseñanza de la moral tampoco estuvo exenta de las tensiones dentro y fuera del taller. Muchos jóvenes huían o terminaban los contratos debido a la excesiva disciplina que ejercían los maestros sobre ellos (Somohano, 200I). Los castigos y los golpes fueron una constante en este disciplinamiento. Incluso se sabe que muchos oficiales también 
ejercieron violencia en contra de sus compañeros, so pretexto de corregir malos comportamientos.

La educación artesana durante el periodo novohispano fue mucho más compleja, crearon identidades y las reforzaron a través de prácticas diarias. Es necesario comprender que la educación y las prácticas artesanas cotidianas permitieron elaborar una serie de representaciones sobre lo que significó ser artesano. Si bien es necesario establecer puentes entre la transmisión de conocimientos prácticos y posteriormente su institucionalización, estos no se hubieran podido dar sin la serie de símbolos y significados que se construyeron dentro y fuera de los talleres.

\section{Referencias}

AHCM [Archivo Histórico de la Ciudad de México]. (s/f). Copia que informa sobre los escribanos de esta Audiencia Ordinaria y que a ninguno se le despache título sin haber comprobado su legitimidad y limpieza de sangre [Fondo; Ayuntamiento, Gobiernos del distrito Federal, Escribanos: notarios de la ciudad, vol. 470I, exp. 4]. Ciudad de México.

AHCM. (s/f). Ordenanzas del gremio de sombrereros [Fondo: Ayuntamiento, Gobiernos del Distrito Federal, Artesanos/Gremios, vol. 38I, exp. I]. Ciudad de México.

AHCM. (I752). Joachin Alvares de Cárdenas presenta su acta de examen en el arte de tintorero [Fondo: Ayuntamiento, Gobiernos del Distrito Federal, Artesanos/Gremios, vol.38I, exp.6.6]. Ciudad de México.

AHCM. (I753). Ordenanzas del Oficio y Gremio de los Gamuseros hechas este año de I753 [Fondo: Ayuntamiento, Gobiernos del Distrito Federal, Artesanos/Gremios, vol. 38I, exp. 6.2.]. Ciudad de México.

AHCM. (I770). Libro de exámenes de maestros, y oficios de esta Nobilísima Ciudad perteneciente a la oficina de su Cabildo [Fondo: 
Ayuntamiento, Gobiernos del Distrito Federal, Artesanos/Gremios, vol. 382]. Ciudad de México.

AHCM. (I828). Sobre establecimiento de un tribunal para su corrección [Fondo: Ayuntamiento, Vagos, vol. 45I, exp. 6]. Ciudad de México.

AHCM. (I829). Contra Juan Guerrero y Pedro Salinas [Fondo: Ayuntamiento, Vagos, vol. 45I, exp. I5]. Ciudad de México.

AHNM. [Archivo Histórico de Notarias de México]. (I793). Arroyo Bernardo de Quiroz José Joaquín [Notaría 30, vol. 8]. Ciudad de México.

AHNM. (I79I). Alba Ignacio Javier [Notaría 3I, vol. 3]. Ciudad de México.

AHNM. (1786). Barrio Ignacio María, [Notaría 83, vol. I]. Ciudad de México.

Barrio del, F. (I92I) Ordenanzas de gremios de la Nueva España. Compendio de los tres tomos de la compilación de Nuevas Ordenanzas de la Muy Noble, Insigne y Muy Leal e Imperial Ciudad de México. México: dirección de Talleres Gráficos.

Carrera, M. (1954). Los Gremios mexicanos. La organización gremial en Nueva España I52I-I82I. México: EDIPASA.

Castro, F. (1986). La extinción de la artesanía gremial. México: Universidad Nacional Autónoma de México.

Campomanes, P. (I774). Discurso sobre la educación popular de los artesanos y su fomento. Madrid: Imprenta de Don Antonio Sancha.

Darnton, R. (20I8). La gran matanza de los gatos y otros episodios en la historia de la cultura francesa. México: Fondo de Cultura Económica.

Gonzalbo, P. (2012). Los primeros siglos de la Nueva España. En P. Gonzalbo y A. Staples (coords.), Historia de la educación en la Ciudad de México (pp. 49-II7). México: Secretaría de Educación del Distrito Federal/El Colegio de México. 
Guerrero, (I779). Las ciencias, artes y oficios. Discurso académico: De la conexión que tienen las Ciencias con las Artes, y Oficios: y si una Nación hará progresos en estos sin el previo consentimiento de aquellas. Sevilla: En la Oficina de D. Manuel Nicolás Vázquez y Compañía.

Jovellanos, G. (1865). Obras completas del excelentísimo señor D. Gaspar Melchor de Jovellanos ilustradas con numerosas notas y dispuestas por órden de materias en un plan claro y ameno, aumentadas además con un considerable caudal descritos del Autor dignos de la luz publica é impresos colectivamente por primera vez, con la vida de Jovellanos. Barcelona: Librería de Anticuaria de Antonio Llordachs.

Kropotkin, P. (1989). El apoyo mutuo. Un factor de evolución. Móstoles: Ediciones Madre Tierra.

Lave, J. (200I). Introducción. En S. Chaiklin, y J. Lave, (comps.), Estudiar las prácticas. Perspectivas sobre actividad y contexto. Buenos Aires: Amorrortu Editores.

Lave, J. (1993). Apprenticeship in critical etnographic practice. Chicago: University of Chicago Press.

Mota, A. (2004). La indumentaria de la población civil en la Ciudad de México I8Io-I850 [Tesis de maestría]. Universidad Autónoma Metropolitana, México.

Palacio, R. (I778). Discurso Económico-político en defensa del trabajo mecánico de los menestrales, y de la influencia de sus gremios en las costumbres populares, conservación de las artes, y honor de los artesanos. Madrid: En la Imprenta D, Antonio de Sancha.

Pérez Toledo, S. (1996). Los hijos del trabajo. Los artesanos de la Ciudad de México, I780-I853. México: Universidad Autónoma Metropolitana/El Colegio de México.

Pérez Toledo, S. (I993). Los vagos de la ciudad de México y el Tribunal de Vagos en la primera mitad del siglo XIX. Secuencia, (27), pp. 27-42. 
Pierrotti, N. (2015). La inmigración europea y el arte de enseñar oficios en los orígenes de la industria manufacturera uruguaya (I726I860). Red Internacional de Estudios sobre Sociedad, Naturaleza y Desarrollo, (3I), I06-I22.

Real Academia Española. (I726). Diccionario de la lengua Castellana en que se explica el verdadero sentido de las voces, su naturaleza y calidad con las phrases y modos de hablar, los proverbios o refranes y otras cosas convenientes al uso de la lengua. Madrid: En la Imprenta de Francisco del Hierro.

Rocker, R. (1967). La juventud de un rebelde. Puebla: Editorial Cajica.

Sewell, W. (1992). Trabajo y revolución en Francia. El lenguaje del movimiento obrero desde el Antiguo Régimen hasta I848. Madrid: Taurus.

Somohano, L. (200I). Sistemas de aprendizaje gremial en obrajes y talleres artesanales en Querétaro (I780-I8I5). México: Gobierno del estado de Querétaro.

Thompson, E. (1984). Tradición, revuelta y conciencia de clase. Estudios sobre la crisis de la sociedad preindustrial. Barcelona: Crítica.

Torres, G. (2012). La ciudad novohispana. Ensayo sobre su vida política. En A. Rodríguez (coord.), Historia política de la Ciudad de México (Desde su fundación hasta el año 20oo) (pp. 67-I59). México: El Colegio de México.

Ward. B. (1769). Proyecto económico en que se proponen varias providencias, dirigidas a promover los intereses de España, con los medios y fondos necesarios para su planificación. España: Por don Joachin Ibarra, Impresor de Cámara de S.R.

Este artículo se publica bajo una licencia de Creative Commons Reconocimiento-NoComercial 4.0
Internacional, y puede ser usados gratuitamente para fines no comerciales, dando los créditos a los
autores y a la revista.

Debates por la Historia - Artículos 